\title{
Trajetórias do desenvolvimento rural: pesquisa comparativa internacional
}

JAN DOUWE UAN DER PLOEQ"

\section{Resumo}

Este artigo traz uma reflexão crítica sobre a análise comparativa dos processos de desenvolvimento rural no Brasil, na União Europeia e na China. Argumenta-se que os elementos contextuais e/ou as características do processo, em grande parte ignorados em abordagens do tipo estudo de caso (seja porque são mais ou menos invisíveis e/ou porque são mais ou menos autoevidentes), podem vir à tona através de uma abordagem comparativa. Ao mesmo tempo, a natureza específica dos processos singulares de desenvolvimento rural pode, do mesmo modo, ser explicitada por meio de comparações sistematicamente organizadas. Assim, os atuais processos de desenvolvimento rural são caracterizados como um conjunto de respostas às falhas de mercado - um conjunto de respostas que requer e envolve a construção ativa de novos mercados aninhados.

Palavras-chave: Desenvolvimento rural. Brasil. China. União Europeia. Mercados aninhados. Análise comparativa.

\footnotetext{
1 Tradução de Regina Beatriz Vargas.

* Professor de Estudos de Transição, Universidade de Wageningen, Holanda e Professor Adjunto de Sociologia Rural na Universidade Agrícola de Beijing, China.
} 


\section{Introdução}

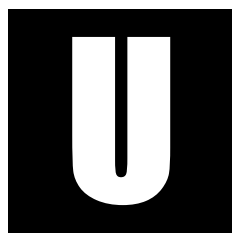

$\mathrm{m}$ dos novos desafios que emergem atualmente no campo de estudos do desenvolvimento rural assenta-se na possibilidade de uma criteriosa comparação dos processos de desenvolvimento rural que estão surgindo em distintos países e continentes. Muitas dessas trajetórias de desenvolvimento estão agora amplamente documentadas; há informação abundante, embora um tanto dispersa, sobre objetivos, mecanismos, direcionadores, políticas e impacto. Entretanto, as dificuldades implicadas em tal exercício comparativo vão muito além dos recursos do manuseio de dados. Elas são, sobretudo, de natureza conceitual e metodológica. Isto se reflete em duas questões centrais: a primeira, o que é desenvolvimento rural? A segunda (supondo que uma resposta satisfatória tenha sido elaborada para a primeira questão): é possível a comparação direta entre processos de desenvolvimento rural de lugares eminentemente distintos, no que concerne às principais dimensões que possivelmente condicionam, ou mesmo ordenam, tais processos?

A noção de desenvolvimento rural é frequentemente entendida como sendo a síntese mais ou menos concisa do que ocorre no rural. Tal noção não é necessariamente errônea; e muitos estudos significativos se têm baseado neste, em geral implícito, ponto de partida. Ela permite incluir dimensões interessantes, bem como fazer comparações entre, por exemplo, diferentes regiões (Kagyama, 2008). Há, contudo, um duplo problema:

(a) 'Aquilo que ocorre no espaço rural' quase nunca pode ser tomado como o simples resultado de atividades, práticas e subprocessos mais ou menos alinhados. O rural é, antes, um amálgama de práticas heterogêneas, estilos mutuamente contrastantes, tendências de desenvolvimento divergentes, posições hegemônicas e mudanças 
quase subterrâneas que, a princípio, são praticamente imperceptíveis, mas que, por fim, podem mudar a paisagem. Há contradições em profusão neste mosaico, de modo que uma narrativa global e unidirecional pode tornar-se menos convincente (ou mesmo completamente míope). Isto ocorre, particularmente, quando existem processos de desenvolvimento que se contrapõem e que competem mutuamente no espaço rural.

(b) Além disso, a noção de 'desenvolvimento rural' é operada, nas múltiplas práticas que juntas constituem o rural, como um conceito normativo. Na prática, tal conceito não pretende simplesmente sintetizar e alinhar o que está em curso. Antes, busca marcar a diferença. E, embora não haja uma razão a priori para realizar a análise da intencionalidade que atores específicos (sejam eles estatais, movimentos rurais ou redes de agricultores e de consumidores etc.) atribuem aos ou investem nos processos de desenvolvimento rural, desconsiderar totalmente as diferentes posições e projetos também seria leviano - ainda mais, tendo em vista que estes últimos podem efetivamente conduzir, pelo menos em parte, o que está ocorrendo. Isto é especialmente verdadeiro quando, entre vários processos de desenvolvimento distintos, uma trajetória específica é rotulada de desenvolvimento rural.

Junto a este primeiro nível de complexidades, há um segundo, relativo ao papel do Estado. Embora o Estado e as instituições estatais desempenhem, indubitavelmente, um importante papel nos processos de desenvolvimento rural, estes últimos não podem ser conceptualizados e estudados como sendo o resultado geral da implementação de políticas de desenvolvimento rural. Aqui, uma vez mais, reside um duplo problema:

(c) No cerne dos processos de desenvolvimento rural há confluências complexas entre suas práticas, concebidas e propagadas no nível local, e suas políticas, que visam coordenar, regulamentar e/ou reorien- 
tar um sem número de práticas heterogêneas de desenvolvimento rural. Estas políticas podem desencadear novas práticas (ou fortalecer as existentes), assim como as práticas de desenvolvimento rural podem induzir novas políticas. A questão, então, é que seria absurdo pressupor a coincidência entre os objetivos das práticas e das políticas (assim como seria inadequado supor de saída que eles estarão em desacordo). O crucial é que haverá, nas distintas interfaces entre o Estado e os operadores do desenvolvimento rural, processos contínuos de interpretação, negociação, renegociação e tradução (Long, 2001). Consequentemente, as políticas serão transformadas: os resultados finais poderão diferir dos objetivos inicialmente planejados.

(d) Movimentos sociais, empresas e redes de atores operam paralelamente às instituições estatais na produção dos processos de desenvolvimento rural. A presença, o poder e a capacidade inovadora desses atores serão distintos de um lugar para outro, assim como as coalizões e/ou confrontos em que eles se engajam irão diferir consideravelmente. Isto afetará o impacto de seus esforços conjuntos. No entanto, este impacto (diferencial) poderá extrapolar os (ou diferir dos) diferentes objetivos que inspiram as várias ações individuais.

Os dois últimos pontos evidenciam que uma análise comparativa dos processos de desenvolvimento rural não pode, absolutamente, se restringir à implementação de políticas de desenvolvimento rural; sobretudo, porque estas são vistas como uma aplicação mais ou menos bem sucedida dos objetivos perseguidos pelo estado (como, em geral, se faz em práticas de avaliação), que podem não ser os mesmos dos atores sociais envolvidos. 


\section{Sobre a abordagem comparativa}

Aplicada corretamente, a abordagem comparativa poderá ajudar muito a lidar com as complexidades e dificuldades mencionadas ${ }^{2}$. Quando as descrições disponíveis dos processos de desenvolvimento rural estão fortemente associadas a localizações no espaço e no tempo, o método comparativo pode ser útil para 'extrair' a essência do desenvolvimento rural como uma categoria geral. Ademais, quando não há uma definição geral aceitável para desenvolvimento rural, a abordagem comparativa pode ajudar a avaliar o que é comum - bem como ajudar a identificar especificidades e dessemelhanças. A sociologia rural tem se debatido, desde seu surgimento, com a complexidade e a mudança. Assim, seus fundadores dedicaram considerável atenção ao método comparativo $^{3}$, e a aplicação sistemática deste ainda fundamenta vários dos melhores produtos que esta disciplina hoje proporciona.

Ao longo das últimas seis décadas, houve diferentes gerações de políticas de desenvolvimento rural. As gerações mudam (como demonstram de modo convincente Ellis e Biggs, em uma revisão da literatura publicada em 2001), como mudam também os mecanismos e práticas favoritos, característicos de cada geração. O rótulo geral, contudo, continuou o mesmo. Uma relação similar, algo confusa, entre o geral e o específico, entre rótulos singulares e práticas heterogêneas, se evidencia quando a di-

2 De um modo geral, uma análise comparativa pode desenrolar-se em duas direções. Pode encaminhar-se para o 'geral': neste caso, a análise é usada para avaliar as propriedades compartilhadas por todas as unidades que, juntas, compõem o conjunto de dados. A análise também pode encaminhar-se para o 'específico': ser usada para avaliar as principais diferenças existentes entre as unidades de análise. Muitas vezes estes dois movimentos estão combinados: um conjunto de características comuns é examinado, ao mesmo tempo em que as principais diferenças são especificadas. Aqui, apresentaremos, inicialmente, um movimento direcionado ao 'geral'. O movimento oposto, em direção ao 'específico', será discutido mais adiante neste artigo.

3 Ver, por exemplo, Hofstee (1985) sobre sociologia diferencial. 
versidade geográfica é considerada. Em constelações tão diferentes como China, Brasil e União Europeia, encontram-se hoje políticas de desenvolvimento rural fortemente institucionalizadas. Tais políticas existem paralelamente às políticas agrárias vigentes. A União Europeia possui um Eixo 1 que representa as políticas agrárias (em constante mudança) e, paralelamente a este, um Eixo 2 que visa ao desenvolvimento rural. Cada eixo possui seus próprios objetivos, modalidades, atores sociais e discurso.

Uma distinção similar é encontrada no Brasil, onde, juntamente com o Ministério da Agricultura, existe outro - o Ministério do Desenvolvimento Agrário. O último visa explicitamente ao desenvolvimento rural. $\mathrm{Na}$ China, à primeira vista, a situação parece ser bem diferente. Existe um marco dominante de política: a 'construção de um meio rural socialista'. Contudo, este marco geral se apóia, e dá continuidade, à política anterior, a san nong, que objetiva tratar de forma integral os 'três problemas rurais'. Estes são: a necessidade de aumentar continuamente a produção agrícola (de modo a manter a soberania alimentar), a necessidade de ampliar a renda dos camponeses (para evitar grandes desequilíbrios entre a cidade e o campo e, cada vez mais, expandir o mercado interno) e a necessidade de criar um ambiente atrativo no campo (frequentemente ilustrado com a metáfora da 'aldeia limpa'). O primeiro 'problema' se refere, evidentemente, ao que alhures é considerado uma política agrícola. O terceiro é o domínio tradicional das políticas de desenvolvimento rural. Já, o segundo pode ser considerado um ponto comum: é visado e impactado tanto pelas políticas agrícolas como pelas rurais. Assim como no Brasil e na UE, estas políticas rurais estão recebendo uma parcela cada vez maior dos orçamentos destinados ao meio rural.

Exceto por estas semelhanças visíveis em um primeiro exame (nas três constelações há, independentemente de todas as diferenças, uma política rural alinhada com uma política agrícola), parece existir apenas 
grandes diferenças. Cada política de desenvolvimento rural possui seu próprio discurso e seus próprios objetivos. A União Europeia busca salvaguardar, através de sua política de desenvolvimento rural, as muitas 'externalidades positivas' que sempre estiveram e ainda estão, embora parcialmente, associadas à agricultura: lindas paisagens, um meio rural ativo, biodiversidade e um ambiente limpo, isto é, não contaminado. No Brasil, em vez disso, a luta contra os desequilíbrios sociais e espaciais e o fortalecimento do altamente diverso, mas em contínuo crescimento, setor da agricultura familiar é que são centrais para o desenvolvimento rural. Já, na China, é ainda um outro discurso que define desenvolvimento rural, o qual poderia ser sintetizado, ainda que de forma pouco ortodoxa, como a integração dos camponeses como cidadãos na China moderna (ou, de modo ainda menos ortodoxo, como uma política para apaziguar seu imenso campesinato).

Quando a atenção científica está focada em uma única constelação (seja ela o Brasil, a China ou a UE), mostra-se muito difícil ir além do discurso político reinante. O risco é o de que a análise científica venha a reificar-se: que reitere os objetivos enunciados, os discuta, avalie o impacto dos programas associados. Ou, que 'desmistifique' estes objetivos e programas ao concluir (ou declarar) que eles pertencem, principalmente, ao domínio da retórica e da ineficiência. Seja como for, a análise segue confinada aos objetivos institucionalmente definidos provavelmente se torna, até mesmo, parte deles (o que, afinal, não é em si um inconveniente para vários dos interesses envolvidos; embora, sem dúvida, esteja em desacordo com a boa ciência).

A única possibilidade de ultrapassar este efeito de aprisionamento (lock-in) é através de uma abordagem comparativa meticulosamente aplicada. Para tanto, é estratégica a noção de que objetivos socialmente construídos e limitados no tempo e no espaço podem referir-se a (assim como encobrir) 
um conjunto (ou espaço) subjacente de aspectos comuns. Desvelar tal espaço de características comuns (e, portanto, contribuir para a melhor compreensão de um mundo aparentemente caótico) é o aporte que a boa ciência pode trazer através do método comparativo. Especialmente, porque a descrição dos aspectos comuns ajuda também a especificar as verdadeiras diferenças e a medir o que é único a cada constelação particular.

Neste sentido, é essencial ter questões orientadoras que, em nosso caso, poderiam ser as seguintes:

a) Porque, em diferentes épocas e em diferentes constelações espaciais (ou geopolíticas), de quando em quando, existem práticas, processos e políticas de desenvolvimento rural?

b) O que essas práticas, processos e/ou políticas têm em comum (se é que têm)?

c) Quando percebidas a partir dos efeitos produzidos (i.e., práticas alteradas, um impacto específico etc.), o que, então, se pode dizer sobre aspectos comuns e sobre diferenças?

d) Quais são as origens específicas das quais emergem estas práticas e políticas? Como elas estão evoluindo? Como estão operando no contexto mais amplo? Que coalizões e que tipos de arranjos institucionais estão emergindo? Quais os principais meios empregados?

Fica evidente que tal rol de questões orientadoras pode ser consideravelmente ampliado (e tem de ser adaptado às especificidades dos objetos estudados). O ponto crucial, no entanto, é que as comparações, construídas segundo o modo indicado, possibilitam generalizações empiricamente fundamentadas sobre a questão que é objeto da abordagem comparativa. A análise, portanto, pode ir além das diferenças historicamente produzidas e/ou socialmente construídas que, de outro modo, a condicionariam e limitariam (i.e. restringiriam). Esta pode, então, ser con- 
duzida sem ter de encaixar-se em uma gama de pressupostos a priori que, igualmente, iriam enviesá-la desde o princípio.

\section{Brasil , China e a União Europeia}

Ao longo dos últimos cinco anos, tenho tido o prazer de trabalhar em tal análise comparativa do desenvolvimento rural com um grupo internacional de pesquisadores acadêmicos da Europa, do Brasil e da China. O denominador comum (ou espaço de aspectos partilhados) que encontramos é, em primeiro lugar, o de que o desenvolvimento rural consiste, basicamente, em um conjunto de respostas mais ou menos coerentes às falhas de mercado. Em segundo lugar, o de que estas respostas, sobretudo, embora não exclusivamente, implicam a e evoluem através da construção de novos mercados e/ou novos padrões de governança para os mercados existentes (Ploeg, Ye \& Schneider, 2011b).

Embora possa parecer paradoxal, esta aparente contradição reflete uma crescente dualidade que será observada em todas as três constelações. Por um lado, existem mercados de produtos básicos (commodities) globalizados e liberalizados para produtos agrícolas e os alimentos. Estes são os mercados que, cada vez mais, geram as já mencionadas falhas de mercado: desigualdades sociais e espaciais agudas (Brasil), a ameaça da marginalização do campesinato (China) e a destruição das paisagens, da biodiversidade e da qualidade de vida no campo (União Europeia). Por outro lado, há novos mercados emergindo ${ }^{4}$. Estes são mercados particu-

4 A conceptualização desses mercados emergentes é outro resultado da análise comparativa. Esta revelou que a análise de um conjunto mais amplo de tais mercados, que operam sob condições claramente diferentes, permite a especificação de uma gama de características (ver, por ex. Ventura \& Ploeg, 2011 e Polman et al, 2011) que jamais poderiam derivar da análise de um único mercado. Outro exemplo da abordagem comparativa dos mercados de alimentos é trazido em Roep e Wiskerke,(2008). 
larmente diferentes dos mercados de commodities. Os novos mercados emergentes centram-se, muitas vezes, na demanda por e distribuição de produtos e serviços que portam um diferencial. Eles diferem dos demais que circulam nos mercados de commodities: a qualidade é superior; a origem é conhecida (se comparada aos produtos anônimos dos mercados de commodities); sua produção é diferente e incorpora características específicas no produto; incorporam relações diferentes entre produtores e consumidores; representam diversos graus de acessibilidade; etc. Além disso, em sua maior parte, os mercados emergentes implicam novos circuitos, novas (e muitas vezes radicalmente diferentes) infraestruturas físicas e arranjos sociais. Eles são governados de modos que contrastam radicalmente com os grandes mercados de produtos agrícolas e alimentares.

A estes mercados emergentes nos referimos como 'mercados aninhados' (nested markets)* (Ploeg, Ye \& Schneider, 2011c; Polman, Poppe, Schans \& Ploeg, 2011). Este termo busca fazer uma dupla descrição. Os novos e emergentes mercados aninhados diferem dos nichos de mercado, porque não são fechados. Ao contrário, eles possuem fronteiras permeáveis. Novos produtores podem entrar (não existe monopólio), assim como o mercado pode se expandir, contrair ou diferenciar-se internamente. Ao mesmo tempo, o mercado aninhado está integrado ao mercado amplo, mas como um segmento específico. É um segmento que possui diferentes inter-relações, distintas dinâmicas e um impacto diferenciado, bem como é governado de modo diverso. Em suma, é um mercado aninhado: consiste de um conjunto específico de transações, envolvendo produtos e serviços

\footnotetext{
* N.T.: A expressão nested markets não encontra em português uma tradução satisfatória, que dê conta do sentido do termo - mercados que estão inseridos um dentro do outro, ao modo das Matryoshkas, as populares bonecas russas, ou de tigelas ou caixas, de diferentes tamanhos, que se acomodam umas dentro de outras. Optou-se aqui pelo termo 'aninhado', que se aproxima desta idéia.
} 
específicos, entre fornecedores e compradores específicos, que obedecem normas específicas e produzem benefícios específicos. Esta especificidade socialmente construída define e reproduz o mercado aninhado. Juntas, as diversas e interconectadas linhas de especificidade criam o 'ninho': o 'invólucro' que protege o que acontece e cresce em seu interior.

Evidentemente, todos os mercados estão imersos em marcos institucionais, todos os mercados contêm e são regulados por modos de governança. A diferença básica, contudo, é que os grandes mercados de produtos agrícolas e alimentares são, cada vez mais, governados por impérios alimentares (que juntos compõem um regime imperial) (Ploeg, 2008 e 2010), ao passo que os mercados emergentes estão inseridos em (e pelo menos em parte governados por) novas redes sociotécnicas que visam a proteger espaços específicos contra o regime imperial e, ao mesmo tempo, possibilitar a construção de trajetórias de desenvolvimento que ultrapassem as limitações inerentes a este regime.

No Brasil, um exemplo par excellence deste emergente mercado aninhado é o mercado de merenda escolar, criado através do Programa Nacional de Alimentação Escolar (PNAE). O PNAE especifica que pelo menos 30\% dos alimentos distribuídos a escolas, hospitais, instituições de caridade, entre outras instituições, devem ser adquiridos localmente de camponeses e agricultores familiares. Em 2010, o PNAE possuía um orçamento de 1,7 bilhões de dólares. Assim, o programa criou um mercado aninhado que tanto sustenta a merenda escolar (um elemento essencial no combate à fome) como, simultaneamente, construiu um canal de distribuição para mais de 300.000 pequenos agricultores (Schneider e Márcia Triches, 2010). O Estado, através do Ministério do Desenvolvimento Agrário e do Fundo Nacional de Desenvolvimento da Educação (FNDE), desempenhou um importante papel na construção deste novo mercado aninhado. O mesmo se aplica ao Programa de Aquisição de Alimentos 
(PAA) (Guareschi, 2010). Há, também, vários exemplos de novos mercados que foram criados e se têm desenvolvido sem maiores intervenções estatais. A experiência da ECOVIDA é uma expressão contundente destes últimos (Ploeg, Ye e Schneider, 2011a).

Junto à criação de novos mercados, há intervenções importantes nos mercados existentes. Como mostram em detalhes Schneider, Belik e Shiki (2011), a desmonopolização dos atuais mercados de terra, crédito e assistência técnica - fortemente conduzida pelos movimentos sociais - e o subsequente "reaninhamento" (re-nesting) desses mercados em novos padrões de governança são características centrais do desenvolvimento rural no Brasil. O mesmo vale para a desvinculação entre a agricultura e os grandes mercados de agroquímicos - uma mudança conduzida pelo movimento agroecológico (Petersen, 2009).

Na União Europeia, vários novos mercados aninhados desenvolveram-se nas últimas décadas ${ }^{5}$. Há mercados para (1) produtos regionais, (2) produtos de alta qualidade, (3) produtos orgânicos e (4) energia limpa, e para serviços como (5) a venda de alimentos através de cadeias curtas e localizadas, (6) agroturismo e (7) atividades de assistência, todos eles caracterizados por produtores e consumidores particulares. O único envolvimento do Estado nestes mercados é com o propósito de regulá-los. Apenas os mercados para (8) a manutenção de paisagens e (9) de recursos naturais valiosos e da biodiversidade são caracterizados por uma forte, embora não exclusiva, demanda por parte de estado. Mesmo nestes dois últimos casos, processos significativos de desmonopolização e de descentralização estão em curso, levando a "quase mercados". Iniciativas civis e organizações da sociedade civil têm se envolvido cada vez mais nesses

5 Estes novos mercados, suas estruturas e dinâmicas são exaustivamente discutidos em Oostindie et al, 2011. 
"quase mercados", e muitos agricultores buscam fontes alternativas de remuneração (por exemplo, vinculando a manutenção da paisagem ao agroturismo e venda local de produtos agrícolas. Embora possa ser um erro elementar afirmar que o desenvolvimento rural na Europa está essencialmente voltado ao mercado, parece que ele ocorre, em sua maior parte, por meio de novos mercados criados a partir do próprio processo de desenvolvimento rural; ao mesmo tempo, ele representa um distanciamento dos grandes mercados de produtos primários, crescentemente controlados por diferentes impérios alimentares.Em sua análise dos processos de desenvolvimento rural na China, Ye et al (2010) se referem aos seguintes novos mercados que emergiram no contexto do desenvolvimento rural:

(1) o mercado de alimentos orgânicos (que atualmente abarca mais de 500 variedades de produtos, em sua maioria, exportados; o valor de exportação é de cerca de 400 milhões de dólares americanos);

(2) o mercado de alimentos verdes (Green Food) que distribui alimentos certificados na China (vendas deste mercado totalizam hoje 19 bilhões de Euros/ano);

(3) o mercado da ecoagricultura que se apóia, em boa parte, nas antigas tradições agrícolas;

(4) os mercados associados ao programa "Uma Aldeia, Um Produto" (estes mercados estão focados principalmente em produtos típicos do local ou da região como, por exemplo, tofu de alta qualidade ou maçãs colhidas manualmente; fábricas de alimentícios e restaurantes locais são bases importantes para estes mercados);

(5) os mercados do agroturismo (há cinco tipos diferentes de agroturismo na China; juntos eles atenderam 335 milhões de turistas em 2007; geram uma renda de cerca de 5 bilhões de Euros/ano). 
Neste mesmo artigo, Ye et al (2010) se referem a algumas características comuns destes novos mercados aninhados. Primeiro, tais mercados são desenvolvidos de forma paulatina. Iniciam como experimentos, que muitas vezes são promovidos por camponeses, e acabam sendo integrados aos marcos das políticas. Em suma, estes novos mercados emergem de processos complexos e multifacetados de experimentação, aprendizagem, ajustamento e, por fim, institucionalização. Em segundo lugar, uma vez estabelecidos, tais mercados funcionam claramente como 'diques de proteção' vis-à-vis importações de baixo custo. As vantagens locais (relativas a recursos culturais e agrícolas locais) são, em geral, estratégicas neste sentido. Em terceiro lugar, os recursos adicionais exigidos são alocados através de apoio governamental. Esta é uma diferença importante em relação à Europa. Finalmente, a multifuncionalidade é, muitas vezes, central para estes novos mercados. Em síntese: tais novos mercados estão de fato aninhados em uma estrutura na qual recursos locais, desenvolvidos passo a passo, determinam culturalmente necessidades e expectativas que, juntas, têm um papel estratégico na assistência suplementar do Estado e na multifuncionalidade.

Novas formas de governança que induzem novas dinâmicas nos mercados existentes são igualmente importantes na China. Elas emergem, entre outras coisas, através da elaboração de novas e inteligentes formas de políticas rurais e agrícolas. Seu melhor resultado é que as relações de troca entre cidade e campo (entre agricultura e indústria) literalmente se reverteram ao longo dos últimos 6 anos, em benefício do campo e da agricultura. O princípio político de 'dar mais e tomar menos' (inicialmente formulado em setembro de 2002 e reafirmado nos Documentos Centrais No 1 de 2004 e 2005) tiveram um papel crucial nesta reversão. A nova tendência foi reforçada recentemente, através da tentativa de ampliar o mercado interno chinês com o propósito de reduzir a dependência das exportações. 


\section{O peixe e a água}

Em retrospectiva, pode parecer surpreendente ter sido necessária uma análise comparativa ampliada para entender e representar os processos de desenvolvimento rural como conjunto, multifacetado e relativamente harmônico de respostas às falhas de mercado - um conjunto de respostas que requer e envolve a criação de novos mercados aninhados (Ventura \& Ploeg, 2001, p. 2). Enfim, parece evidente que a produção de novos bens e serviços pressupõe, ao final, a construção de novos mercados (uma vez que sua comercialização através de amplos mercados de commodities seria impraticável ou implicaria uma grande expropriação do valor agregado encerrado nesses novos produtos e serviços). Seja como for, a pesquisa, aqui brevemente descrita, resultou na primeira análise científica a colocar a centralidade dos mercados no centro do debate.

Olhando para trás, pode-se concluir que os projetos de pesquisa que enfocam um único país tendem a enfatizar (e superdimensionar) o papel das políticas de desenvolvimento rural. Além disso, tendem a refletir a especificidade dos objetivos dessas políticas em sua análise das práticas, processos e resultados associados ${ }^{6}$. Isto parece ser quase inerente a estudos de um só país (que não estejam incorporados em um marco comparativo mais amplo). Também fica evidente, em boa parte do meu próprio trabalho anterior, assim como daquele de outros colegas que participaram da análise comparativa discutida aqui.

Há outras características que fortalecem esta tendência. O 'mercado' é facilmente tomado como uma categoria indiferenciada em estudos de um único país - sobretudo, porque há poucas conceptualizações ade-

6 Ainda mais, porque frequentemente baseiam-se em dados coletados e organizados por instituições governamentais envolvidas no monitoramento e na avaliação das políticas de desenvolvimento rural. 
quadas na teoria neoclássica. Como argumentam Huylenbroeck et al.: tentativas de captar o quê, exatamente, é um mercado são surpreendentemente raras (2009, p. 176). Neste sentido, eles fazem eco a Stigler que já afirmava, há mais de quatro décadas, que é uma fonte de constrangimentos o fato de que tão pouca atenção tenha sido dada à teoria dos mercados $\left(1967\right.$, p. 29) ${ }^{7}$. As abordagens marxistas encontram a mesma dificuldade para centrar no mercado como uma arena de luta sociopolítica e para representar mercados aninhados, recém construídos, como um importante mecanismo de luta por emancipação ${ }^{8}$.

Finalmente, há que fazer referência ao 'poder da autoevidência' (Zijderveld, 1982). União Europeia, Brasil e China são todos exemplos claros de economia de mercado. O mercado é uma característica autoevidente nessas sociedades. É como a água que circunda o peixe. Este último dificilmente estará consciente da importância crucial da água - simplesmente, porque ela sempre esteve lá. E, quando já não estiver, será tarde demais: o peixe estará morrendo. Portanto, conhecer a água é essencial para entender o peixe. Assim, parece evidente que novos bens e novos serviços (resultantes de novas práticas de desenvolvimento rural) sejam mercantilizados. Não parecia ser necessária qualquer outra investigação.

Foi só por meio da análise comparativa de distintas experiências de desenvolvimento rural (na China, no Brasil e na União Europeia) que ficou manifesta a necessidade de examinar aquilo que era 'autoevidente'. Novos bens e serviços eram e são criados, porque os principais mercados

7 Há algumas exceções eloquentes encontradas, principalmente, nos estudos antropológicos de mercados não ocidentais. A abordagem neoinstitucional em economia é outra exceção promissora (ver, especialmente, Saccomandi, 1998).

8 Aqui, mais uma vez, há algumas notáveis exceções: especialmente as noções teóricas de Shanin (1973) ainda se destacam. Exemplos mais recentes encontram-se nos trabalhos de Kervliet, 2009 e de O'Brien, 1996, sobre a política do cotidiano e resistência legítima, especialmente quando as análises focam as formas recentes de luta política no sudeste da Ásia. Para mais informações ver Ploeg, Ye e Schneider 2001a. 
para os produtos padronizados apresentam falhas sistemáticas (devidas, entre outras coisas, à posição central dos impérios alimentares na governança desses mercados). Portanto, a construção de novos mercados emerge como uma arena importante (assim como o distanciamento de outros mercados, como o de agroquímicos, e o desenvolvimento de novas formas de governança para os mercados existentes). Consequentemente, a análise comparativa induziu a necessidade de se fazer a distinção teórica entre diferentes mercados e diferentes formas de governança, bem como de avaliar com clareza os padrões em que se fundam tais diferenças (ver Ventura e Ploeg, 2011; Ploeg, Ye e Schneider, 2011c).

\section{Rumo ao 'específico'}

Os processos de desenvolvimento rural tanto remodelam as práticas de agricultura como são resultado de práticas mutantes nesta área. Uma vez que essas mudanças serão parciais (só ocorrerão em uma parte do setor agrícola), desiguais (algumas práticas de desenvolvimento rural serão mais desenvolvidas do que outras) e diferenciadas (práticas de desenvolvimento rural estão longe de ser uniformes; são, ao contrário, multidirecionais), o desenvolvimento rural certamente contribuirá para ampliar a heterogeneidade do setor agrícola, assim como é, em si, um processo heterogêneo. Ou seja, os estilos de agricultura vigentes serão afetados, tão logo surjam novos estilos de agricultura (enquanto outros poderão desaparecer).

Um estilo de agricultura consiste em um modo específico e internamente coerente de agricultura. É uma forma distinta e válida de produção agrícola compartilhada por um grande grupo de agricultores; neste sentido, representa um aspecto em comum (ainda que em um nível diferente daquele considerado central na comparação inter-países discutida acima). É agricultura estruturada (ou ordenada) de um modo 
específico; uma forma particular de ordenamento (Law, 1994) que pode ser diferenciada de modelos antagônicos. Em nossa primeira publicação sobre estilos de agricultura, delimitamos a noção destes estilos referindo-nos às diferentes opiniões sobre como a agricultura deveria ser organizada e às diferenças associadas à prática da agricultura (van der Ploeg e Roep, 1990, p. 1). Portanto, desde o princípio, o conceito se referia tanto à dimensão normativa quanto àquela material da agricultura - entendendo a última, em certa medida, como uma expressão e uma reafirmação da primeira ${ }^{9}$. Em seu conjunto, diferentes estilos de agricultura conduzem a e explicam a grande heterogeneidade da agricultura que pode ser encontrada em determinados cenários.

Assim, um estilo de agricultura consiste em um certo padrão de vinculação entre terra, trabalho, gado, máquinas, redes, conhecimento, expectativas e atividades, feito de forma informada e coerente, orientada a objetivos. É um modo particular de combinar, utilizar e desenvolver os recursos agrícolas, tanto sociais como materiais. Em outras palavras, um estilo de agricultura é um modo particular de padronizar (no nível micro) os mundos social e material, de forma coerente e autossustentável. Em suma, é um fluxo de atividades organizado ao longo do tempo (como reafirmado recentemente na fascinante pesquisa agro-histórica de Garstenauer et al., 2010).

Enquanto as ciências agrícolas de hoje apresentam forte tendência para a definição de um único ótimo (mais comumente definido pelo uso

\footnotetext{
$9 \mathrm{Na}$ ocasião, este era um delineamento importante entre as então dominantes posições teóricas (fundamentalmente originadas da economia neoclássica) que focavam nos "tipos agrícolas" e no "comportamento empreendedor". Em Roep, van der Ploeg e Leeuwis (1991:3), explicamos que estilos de agricultura são "práticas sociais distintas" que são dinâmicas, parcialmente enraizadas na história e que integram as dimensões material e simbólica. Afirmamos explicitamente "que estilos de agricultura não dizem respeito a indivíduos" (op. cit., pág. 4). Em publicações posteriores colocamos muita ênfase no elemento 'autoclassificação' (ver, p.ex., Leeuwis, 1993).
} 
de parâmetros econômicos e tecnológicos), estilos de agricultura ilustram a construção social de um espectro mais amplo de distintos ótimos. Neste sentido, refletem a sabedoria da vida cotidiana (ou conhecimento tácito) de que "há mais caminhos que levam a Roma". Isto está ilustrado na Figura 1, que mostra como as fazendas holandesas de gado leiteiro se desenvolveram (no período 1969-1981), segundo dimensões de escala e intensidade.

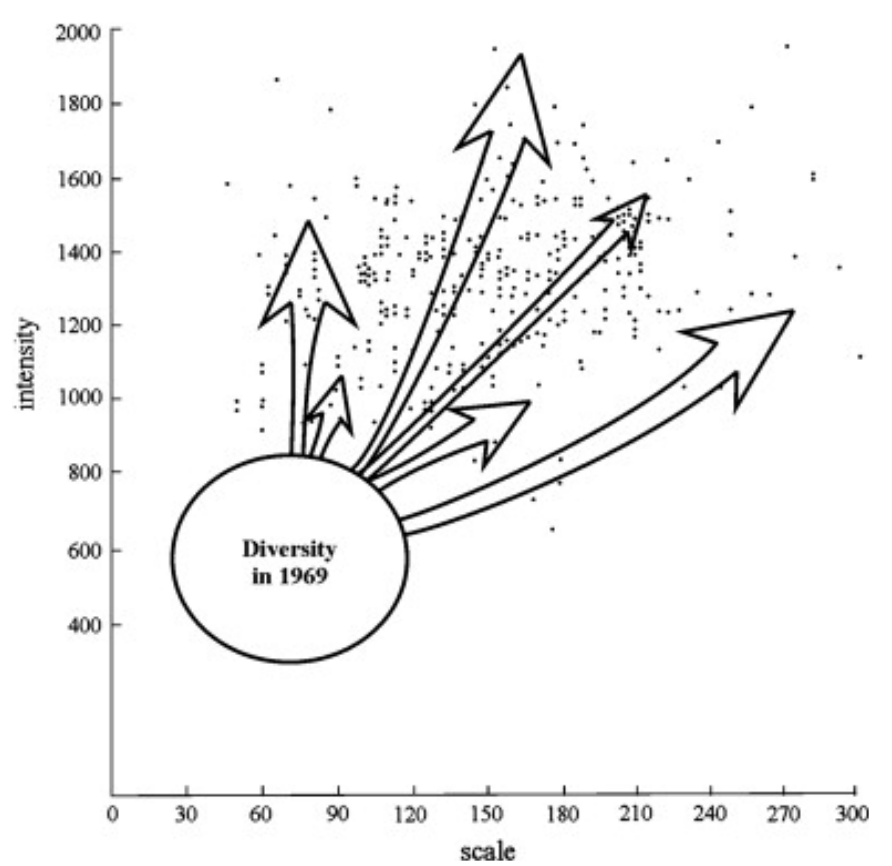

Figura. 1 Trajetórias empíricas de desenvolvimento agrícola no período 1969-1981. 
Os agricultores observam continuamente o contexto em que trabalham - ainda que o façam de formas, em geral, muito diversas. Especialmente quando se referem a períodos mais longos (abarcando um número maior de fenômenos mutuamente compatíveis), observações específicas podem ser traduzidas em novos cursos de ação, isto é, novas estratégias. Ao enfrentar continuamente restrições creditícias à agricultura, os agricultores podem decidir mudar para níveis consideravelmente menores de uso de crédito e insumos externos. Isto pode ocorrer, particularmente, quando novos aumentos de escala (destinados a reduzir preços de custo) parecem progressivamente contra-produtivos ${ }^{10}$. Deste modo, o estilo de agricultura econômica nasceu e se reproduziu na Europa. Isto também se aplica à agroecologia, no que concerne ao Brasil. Estes novos estilos auxiliam os agricultores a enfrentar em melhores condições as falhas de mercados vigentes.

O mesmo se pode dizer da (re)construção da multifuncionalidade (através de processos multifacetados de diversificação): esses processos resultam na emergência de novos estilos de agricultura (inseridos em novas relações com os mercados e a sociedade em geral) e/ou na readaptação dos estilos existentes. Daí, que a heterogeneidade assim ampliada da agricultura presta considerável auxílio para aumentar sua resiliência vis-à-vis o contexto turbulento (ver Minter, 2010, para uma abordagem geral e Wales Rural Observatory, 2010, para uma aplicação), ainda mais quando ocorre juntamente ao desenvolvimento de novos mercados aninhados que representam, no mínimo, uma mudança parcial de contexto. Esta característica (a resiliência ampliada)

10 Como é o que ocorre sob as atuais condições de crise. Por exemplo, na Holanda, os aumentos de escala se traduzem em aumentos nos níveis dos preços de custo e em fluxos de caixa negativos sempre que os preços de venda estão baixos. 
parece aplicar-se também às agroindústrias familiares em forte expansão no Brasil (ver, por exemplo, Schneider, 2006).

No arcabouço do desenvolvimento rural, destacam-se como decisivos, especialmente, os equilíbrios recém construídos entre atividades agrícolas 'tradicionais' (ligadas aos mercados de produtos básicos) e as novas formas de multifuncionalidade (frequentemente, embora nem sempre, ligadas aos mercados aninhados). Distintos equilíbrios se traduzem, progressivamente, em novos e distintos estilos de agricultura. Tais equilíbrios em transformação podem ser estudados, por exemplo, através da diversificação dos padrões de investimento. Oostindie et al. mostram (em pesquisa em curso $)^{11}$ que existe uma marcante diversidade entre empreendimentos agrícolas multifuncionais na Holanda. Alguns utilizam a recém desenvolvida diversificação das atividades para gerar poupanças que são posteriormente investidas na produção padrão de commodities. As primeiras fortalecem as últimas, enquanto as últimas tornam-se, em certa medida, dependentes da primeira. Isto se contrapõe a outros padrões em que a construção de sinergia é fundamental: antigas e novas atividades compõem um novo equilíbrio, através do qual, uma fortalece a outra e vice versa (este caso vem sendo teoricamente elaborado por Saccomandi, 1998). No outro extremo, existem casos em que os fatores (e quotas) de produção usados para a agricultura tradicional são vendidos para construir unidades agrícolas multifuncionais completamente novas.

O desenvolvimento destes novos estilos de agricultura pode induzir novas dinâmicas no setor. Isto é mostrado em recente estudo italiano que se centrou no equilíbrio mutante entre agricultura especializada e agri-

11 Este é o programa de pesquisa sobre a 'Dinâmica e Solidez da Agricultura Multifuncional', que está sendo realizada pela Universidade de Wageningen (Departamento de Sociologia Rural) e financiada pela Força Tarefa de Agricultura Multifuncional do Ministério da Agricultura. 
cultura multifuncional (Ventura, de Rooij e Milone, no prelo). A pesquisa incluiu um levantamento (survey) $(n=1.600)$ entre um grande número de agricultores de dedicação exclusiva, que receberam mais de 15.000 Euros por ano de subsídios diretos. Em 2008 (ano em que a survey foi aplicada), $27 \%$ das unidades agrícolas deste subgrupo específico poderiam ser classificados (segundo os próprios agricultores) como empreendimentos multifuncionais que haviam adotado novas atividades juntamente com as 'tradicionais'. Os restantes $73 \%$ dos empreendimentos eram especializados somente em atividades agrícolas. Deste último grupo, 8\% acreditavam que, dentro de cinco anos, o empreendimento seria fechado. No grupo multifuncional, só $1 \%$ tinha esta expectativa. Treze por cento dos agricultores especializados planejam integrar uma ou mais atividade de desenvolvimento rural em seu empreendimento nos próximos cinco anos. Em conjunto, estas mudanças implicariam que, ao longo dos cinco anos seguintes, a distribuição entre empreendimentos especializados e multifuncionais irá para $57 \%$ de especializados e $43 \%$ de multifuncionais. Quando se consideram os agricultores com menos de 40 anos de idade, a distribuição muda para $49 \%$ e 51\%, respectivamente.

A mesma pesquisa também investigou os padrões de investimento. Dos agricultores especializados, $16 \%$ indicaram que haviam investido ativamente na produção de alimentos ao longo dos últimos cinco anos, menos da metade do número de agricultores multifuncionais que o fizeram (36\%). Para os cinco anos seguintes, 27\% dos agricultores especializados disseram que iriam investir na produção de alimentos, enquanto 44\% entre os multifuncionais planejavam produzir alimentos.

Isto indica que a agricultura multifuncional definitivamente não representa um adieu à agricultura como tal. É, antes, o caminho oposto. Os ganhos obtidos com as novas atividades ajudam os agricultores a continuar e a investir nas atividades clássicas da agricultura. Isto é particu- 
larmente importante na época atual, em que a agricultura está enfrentando as consequências da crise econômica geral. As práticas de desenvolvimento rural se tornam importantes linhas de defesa pra a produção de alimentos (o que se confirma no Wales Rural Observatory, 2010).

Em resumo, a abordagem comparativa contribui para a exploração e identificação de novos padrões de coerência (novos estilos de agricultura) que emergem no e constituem o processo de desenvolvimento rural, e que se traduzem em uma expansão da heterogeneidade global. As novas formas de heterogeneidade são especialmente importantes, na medida em que contribuem para a re-localização da agricultura. Há uma tendência crescente da agricultura de reassentar-se em recursos localmente disponíveis, assim como de estar inserida nos padrões locais e regionais para processamento e distribuição de seus produtos e serviços. No âmbito deste marco emergente, novos parâmetros entram em cena, como, por exemplo, a qualidade do ambiente rural local, a qualidade do trabalho (incorporada, por ex., em trabalho manual, capacidade inovadora ${ }^{12}$ e novas habilidades empresariais), a qualidade das novas redes e coalizões locais e a competência para 'afinar' os estilos de agricultura emergentes. Na medida em que tais qualidades tipicamente locais estejam disponíveis (e adequadamente combinadas), tanto mais efetivas serão as respostas às falhas globais de mercado.

\section{Conclusões}

Neste texto, discuti brevemente a dupla aplicação do método comparativo para os processos atuais de desenvolvimento rural. Este método

\footnotetext{
$12 \mathrm{Na}$ Europa, cada vez mais referimo-nos à produção de novidade (ao invés de capacidade inovadora). Esta última está fortemente associada à adaptação de artefatos prontos para uso e/ou de métodos desenvolvidos por agroindústrias e instituições científicas. O conceito de produção de novidade, por sua vez, está centrado na capacidade de agricultores para produzir, reconhecer, selecionar e utilizar variações que emergem localmente, e expandi-las. Ver Wiskerke e Ploeg, 2004.
} 
possibilita a determinação dos denominadores comuns. Sendo assim, ajuda a compreender os processos de desenvolvimento rural como respostas multifacetadas e de múltiplos níveis às falhas de mercado associadas às dinâmicas dos mercados globais de commodities para a produção agrícola e de alimentos. O método comparativo também permite avaliar os novos e distintos padrões de coerência que emergem tanto no âmbito desses processos de desenvolvimento rural como através deles. Portanto, a abordagem comparativa contribui significativamente para a compreensão dos atuais processos de desenvolvimento rural como fenômenos disseminados, persistentes e resilientes, que podem alterar parcelas consideráveis das realidades rurais - onde quer que estas estejam localizadas. Como sugere a análise comparativa, esta persistência, resiliência e ampla distribuição espacial do desenvolvimento rural (em constelações espaciais tão diversas como Europa, China e Brasil) se deve ao fato do desenvolvimento rural estar radicado tanto em problemas globais (falhas de mercado) como em respostas locais (novas práticas de desenvolvimento rural que se articulam através de novos mercados aninhados) altamente diferenciadas.

A mesma discussão mostra que o método comparativo depende significativamente da formulação adequada das questões de pesquisa, bem como da especificação adequada do nível de análise. Quando ambas as condições são atendidas, tornam-se possíveis generalizações empiricamente fundamentadas e uma especificação da relevante heterogeneidade. Por meio de etapas iterativas, as análises tanto do 'geral' como do 'específico' podem fortalecer-se mutuamente. 


\title{
Rural Development Trajectories: International Comparative Research
}

\begin{abstract}
This paper contains a critical reflection on a comparative analysis of rural development processes in Brazil, the European Union and China. It argues that those contextual elements and/or process characteristics that are mostly ignored by a case-study approach (for being more or less invisible and/or for being more or less self-evident) might come to the fore through a comparative approach. Simultaneously, the particular nature of single rural development processes might equally be specified through systematically organized comparisons. In this way, current rural development processes are characterized as a set of responses to market failures - a set of responses that requires and involves the active construction of new, nested markets.
\end{abstract}

Keywords: Rural development. Nested markets. Comparative analysis. Brazil. China. European Union.

\section{Referências}

ELLIS, F.; BIGGS, S. Evolving Themes in Rural Development 1950s-2000s. Development Policy Review, 2001, 19 (4):437-448, 2001.

GARSTENAUER, R., KICKINGER, S.; LANGTHALER E. The Agrosystemic Space of Farming: analysis of farm records in two lower Austrian regions, 1945-1980s. Trabalho apresentado no workshop Historicising Farming Styles, Melk, October 22-23, 2010.

GUARESCHI, A. A operacionalização da política de segurança alimentar: 0 caso do Programa de Aquisição de Alimentos (PAA) em Tenente Portela/RS. 2010. Dissertação (Mestrado em Desenvolvimento Rural) - Programa de Pós Graduação em Desenvolvimento Rural, UFRGS, Porto Alegre, 2010.

HOFSTEE, E. W. Differentiële sociologie in kort bestek: schets van de differentiële sociologie en haar functie in het concrete sociaal-wetenschappelijke onderzoek. In: HOFSTEE, E. W.; JOLLES, H. M.; GADOUREK, I. Differentiële Sociologie in Discussie. Amsterdam: VUGA, 1985.

HUYLENBROECK, G. van; VUYLSTEKE, A.; VERBEKE, W. Public Good Markets: the possible role of hybrid governance structures in institutions for sustainability. 
In: BECKMAN, V.; PADMANABHAN, M. (Eds.). Institutions and Sustainability. Frankfurt: Springer Science + Business Media B.V., 2009.

KAGYAMA, A. A. Desenvolvimento rural: conceitos e aplicação ao caso brasileiro. Porto Alegre: UFRGS Editora, 2008.

KERKVLIET, Ben. Everyday politics in peasant societies (and ours). Journal of Peasant Studies, 36: 1, p. 227-243, 2009.

LAW, J. Organizing Modernity. Oxford: Blackwell Publishers, 1994.

LEEUWIS, C. Of Computers, Myths and Modeling: the social construction of diversity, knowledge, information and communication technologies in Dutch horticulture and agricultural extension. PhD Thesis, Wageningen University, Wageningen, the Netherlands, 1993.

LONG, N. Development Sociology: actor perspectives. London: Routledge, 2001.

MINTER, T. The Agta of the Northern Sierra Madre: livelihood strategies and resilience among Philippine hunter-gatherers. Ph.D. Manuscript, Faculty of Social Sciences, Leiden University, Leiden, 2010.

O'BRIEN, K. J. Rightful resistance. World Politics, p. 31-56, oct. 1996.

OOSTINDIE, H. et al. The central role of nested markets in rural development in Europe. Artigo aceito por Rivista di Economia Agraria, 2011.

PETERSEN, P. Agriculturas ou Impérios Alimentares? Uma Encruzilhada no Caminho da Humanidade In: PUC Viva, publicação acadêmica e informativa quadrimestral dos professores da PUC-SP, São Paulo, 10-36:11-18, 2009.

PLOEG, J. D. van der. Camponeses e Impérios Alimentares: lutas por autonomia e sustentabilidade na era da globalização. Porto Alegre: UFRGS Editora, 2008.

. The food crisis, industrialized farming and the imperial regime. Journal of Agrarian Change, Vol. 10, no, 1, January 2010, p. 98-106, 2010.

PLOEG, J.D. van der; ROEP, D. Bedrijfsstijlen in de Zuidhollandse veenweidegebieden: nieuwe perspectieven voor beleid en belangenbehartiging. Wageningen, Landbouwuniversiteit, 1990.

PLOEG, J. D. van der; JINGZHONG, Ye; SCHNEIDER, S. Rural development and the construction of new, nested markets (part 2): everyday life politics, common-pool resources and duality. Artigo submetido a The Journal of Peasant Studies, 2011a.

. Rural Development reconsidered: building on comparative perspectives from China, Brazil and the European Union. Artigo aceito por Rivista di Economia Agraria, 2011b.

. Rural development and the construction of new, nested markets (part 1): comparative perspectives from China, Brazil and the European Union. Artigo submetido a The Journal of Peasant Studies, 2011c. 
POLMAN, N. et al. Nested markets with common pool resources in multifunctional agriculture. Artigo aceito por Rivista di Economia Agraria, 2011.

ROEP, D; PLOEG, J.D. van der; LEEUWIS, C. Zicht op Duurzaamheid en kontinuiteit: Bedrijfsstijlen in de Acherhoek. Wageningen, Landbouwuniversiteit, 1991.

ROEP, D.; WISKERKE, H. Nourishing Networks: fourteen lessons about creating sustainable food supply chains. Reed business information, Doetinchem, 2008.

SACCOMANDI, V. Agricultural Market Economics: a neo-institutional analysis of exchange, circulation and distribution of agricultural products. Royal van Gorcum, Assen, the Netherlands, 1998.

SCHNEIDER, S. A diversidade da Agricultura Familiar. Porto Alegre: UFRGS Editora, 2006.

SCHNEIDER, S.; TRICHES, R. M. Short Review of the Brazilian School Feeding Programme - and an example of an innovative way of implementation. 2010. PGDR- UFRGS, Porto Alegre, 2010.

SCHNEIDER, S.; SHIKI, S.; BELIK, W. Rural development in Brazil: overcoming inequalities and building new markets. Artigo aceito por Rivista di Economia Agraria, 2011.

SHANIN, T. The nature and logic of the peasant economy 1: a generalization. Journal of Peasant Studies, 1 (1):63-80, 1973.

STIGLER, G. Imperfection in the capital market. Journal of Political Economy, 75, p. 287-292, 1967.

VENTURA, F.; PLOEG, J. D. van der. Rural Development: some tentative conclusions, Rivista di Economia Agraria, 2011. (no prelo)

VENTURA, F.; ROOIJ, S. J. G. de; MILONE, P. Imprenditori agricoli ed il turno verso la multifunzionalitá. Rome: Donzelli Editori (Forthcoming).

WALES RURAL OBSERVATORY (Arsyllfa Wledig Cymru). A Survey of Farming Households in Wales, Cardiff, Cardiff University, july 2010.

WISKERKE, H.; PLOEG, J.D. van der. Seeds of Transition: essays on novelty production, niches and regimes in agriculture. Royal Van Gorcum, Assen, 2004.

YE, J. Z.; RAO, J.; WU, H. F. 'Crossing the river by feeling the stones': rural development in China. Artigo aceito por Rivista di Economia, 2011.

ZIJDERVELD, A. C. De tirannie van het cliché. Samson, Deventer, 1982.

Recebido: 31/03/2011

Aceite final: 26/04/2011 
